\title{
GOVERNING HIGHER EDUCATION Lessons from Britain for Brazil
}

\author{
GOVERNANDO O ENSINO SUPERIOR \\ Lições da Grã-Bretanha para o Brasil
}

\author{
John Gledhill \\ The University of Manchester \\ School of Social Sciences | Manchester, Inglaterra \\ johngled@me.com | ORCID iD: 0000-0002-4275-2556
}

W

hat Marilyn Strathern (1996) termed "audit culture" has transformed the working lives of university academics, provoking a rising tide of complaint. Yet as Strathern went on to demonstrate by assembling a collection of essays that included audit cultures in other kinds of organizations (Strathern, ed, 2000), it has also proved a fertile field for critical anthropological analysis. The implementation of systems of evaluation and audit in Higher Education has differed in important ways between European countries (Sivertsen 2017), and the United States is a different case again because of the wealth of its elite private universities and more limited role of the federal government (Brenneis 2009). Yet the experience of the United Kingdom has remained prominent in the literature on universities, as a pioneer whose systems have been subject to continuing evolution from which lessons can be learned. My aim here is to draw out lessons relevant to Brazil in a world of university rankings and performance and quality metrics in which academics have been subjected to an "accountability" that has perverse consequences because of its coercive and competitive character, at an individual and institutional level.

I should begin by stating the position from which I write. I have performed many different kinds of evaluations myself, in Mexico as well as in the UK, but have also had opportunities to represent my discipline nationally in negotiations with 
government agencies on the rules of the evaluation processes to be implemented. From 1997 to 2001, I served as Convenor of the (UK) Standing Conference of Heads of Anthropology Departments and was Chair of the Association of Social Anthropologists (ASA) from 2005 to 2009. It is possible to win some battles. We were successful, for example, in defeating the attempt by the UK's first agency charged with auditing the quality of university teaching to treat anthropology as a subdiscipline of sociology. We have certainly not won the war that many anthropologists would like to fight over the way universities are "governed" through audit processes. This is unsurprising given that what has happened to universities is only part of a global transformation of the administration of society and public life (Shore and Wright 2015). "Global" here includes Chinese universities rising inexorably up the world rankings. Yet UK experience shows that organized groups of academics, backed by strong professional bodies, learned societies and national academies, can have some success in resisting attempts by university managers and government bodies to impose demonstrably unsatisfactory metrics-based models for evaluating teaching and research. The rules and procedures governing our periodic national research assessment exercises have changed in important ways over the years, but always following consultation with the academic community. Given that community's ability to question our masters, to date we have not experienced changes in the rules in place at the start of an assessment period during the course of that same period, as happened recently in the case of assessment of postgraduate programs by Capes in Brazil, an assessment in which the very survival of many programs rather than simply their level of financial support is at stake.

Audit culture in British universities was initially a product of Margaret Thatcher's embrace of neoliberal solutions to a postimperial malaise of deindustrialization and economic decline, strongly rooted in the personal ideology of a woman who was not born into the elite establishment and adopted a liberalmeritocratic reading of the arguments of the high priests of the neoliberal alternative to post-war social democratic managed capitalism, Milton Friedman and Friedrich Hayek. A fervent advocate of "downsizing the state" and privatization of public enterprises, Thatcher, who became prime minister in 1979, insisted that "society" did not exist, but only "individuals" who could only prosper by taking responsibility for their own futures. 
One academic consequence of the Prime Minister's views was that the Social Science Research Council was obliged to change its name to the Economic and Research Council, since the Iron Lady insisted that there could be no such thing as a "science" of "society".

In the second half of the 1980s, with neoliberal austerity entrenched, Thatcher's government introduced measures to ensure "accountability and transparency" in the allocation of public funding to universities for research and teaching. Shore and Wright (1999) analysed this as a neoliberal regime of governmentality in the Foucauldian sense (Lemke 2001), essentially coercive in nature but designed to produce disciplined self-regulating subjects through technologies of power in which "government" could be carried out "at a distance", as Nikolas Rose (1999) put it. "Audit" is a term borrowed from finance. The existence of independent auditing bodies clearly has its uses in terms of securing "good government". A recent example is the British National Audit Office's demand for "transparency" from the Boris Johnson government over the billions of pounds sterling that it has disbursed during the Covid-19 crisis to private sector contractors for goods and services, including consultancy, without competitive tender. The failure of many contracts to deliver acceptable results provoked charges of "crony capitalism", since there were personal links between Conservative politicians and many of the companies chosen. Yet the reputations of the four globally dominant financial auditing conglomerates, PWG, EY, Deloitte and KPMG, have themselves not gone unsullied in the years since the Enron scandal and 2008 financial crash. All this invites us to question the core idea of the "New Public Management" paradigm promoted by neoliberal governments, that applying the principles of private business to the public sector will result in efficiency gains and greater "value for money" for the taxpayer. Through the application of "key performance indicators" and their expression in numbers that provide the basis for rankings and league tables, most public services, from schools and hospitals to social care for the elderly, are now evaluated in terms of monetary measures, thereby marrying "scientific management" to "a project of financialization and a new ethics of accountability” (Shore and Wright 2015: 425).

This logic became central in my own university at the start of the new millennium, following the appointment as its head of a controversial promoter of neoliberal new thinking from 
Australia. Even the evaluation of the performance of individual staff came to include a financial measure of "contribution" in terms of research grants, number of students taught and supervised, and other forms of income generated for the institution. University governance was transformed from a collegial into a "top-down" managerial system in which staff could only access the next level in the hierarchy through a designated "line manager". Opportunities to express concerns directly to "senior management" were restricted to infrequent public rituals of consultation with little scope for debate and online surveys of staff "satisfaction". Online surveys are also used locally and nationally to measure student "satisfaction" with their "university experience", their results translated into rankings of departments and institutions.

"Government at a distance" made everyday pressure on academics more intense. They devoted increasing amounts of time to preparing for performance evaluation and "personal development" sessions, participating in obligatory training programs covering corporate agendas as well as core professional tasks, and feeding data into online systems recording a myriad of quantifiable activities, such training and pastoral support offered to students, setting out the goals and expected "learning outcomes" of their courses, the "progress" of their postgraduates, the "outputs" resulting from their own completed research, and their plans for future research. Since gaining competitive externally funded research grants is a "key performance indicator", time needed to be given to application processes that became increasingly complicated as new criteria, including nonacademic impact, were added to the list of issues to be addressed, and internal vetting of proposals increased, although success rates were often below twenty-five per cent. The pressure of audit has obliged staff to work much longer hours per week than those they are contracted to work, to the detriment of family life. Strikes over deteriorating pay and conditions and rising pension contributions and reduced benefits on retirement are more frequent. Yet whilst other university staff have suffered frequent pay freezes, the generous salaries and pension deals of university top management have become a scandal that even the current Conservative government accepts is a problem.

Responsibility for these developments (and parallel deterioration in the UK's universal national healthcare system) cannot, however, be laid entirely at the door of Conservative governments. When the Labour Party returned to power under 
Tony Blair in 1997, his centrist "New Labour" government continued the neoliberalism of its Conservative predecessors with regard to the role of the private sector in health, social welfare and education. Although Blair's version of social democracy did accept the need for government interventions to enhance "equality of opportunity" for young people disadvantaged by class, ethnicity and colour, it retained the neoliberal principle that adult individuals have a moral duty to "market themselves" and accept whatever opportunities the capitalist labour market may offer.

Blair's government reintroduced tuition fees in English public universities, in 1998, replacing the previous system of means-tested maintenance grants with loans for all but the poorest students. The philosophy behind this change was that university graduates as individuals should pay for an education that would enhance their earnings later in life, not the taxpayer. Fees were increased substantially under the LiberalConservative coalition government that ended Labour's tenure of power in 2010, bringing the rationality of the student loans system increasingly into question. The burden of repaying their debt is increasingly crushing on those who do earn enough to repay it. Yet government currently expects that only a quarter of undergraduates will earn enough to repay their loans in full, so much of the burden of financing higher education will return to the taxpayer. This contradiction has, however, prompted the present Conservative government to talk about eliminating "low value" degrees that do not guarantee higher salaries. Humanities subjects are a favourite target, particularly since the issue of their economic benefit to the individual can also be linked to ideological causes dear to Conservative hearts, such as attacking "critical race theory". The low salaries earned by highly qualified people in sectors such as nursing, social care or charitable and non-governmental organizations that would normally be considered beneficial to society, at home and abroad, rarely figure in these debates. Brazilian readers will recognize these arguments, since they have all been articulated under the Bolsonaro government. The issue of the creeping privatization of public universities is also increasingly relevant to Brazil. Fully private universities are of negligible significance in the UK compared with Brazil, but despite the fact that Brazil does have some good private universities as well as many more low-quality ones, public universities are the country's principal centres of 
international research excellence and do most to foster social mobility through broadening access to higher education.

Reductions in government funding have made British universities dependent on tuition fee income and the income that they receive from supplying students with other services, especially accommodation. Tuition fees can be up to 9,250 pounds sterling annually for home students and average between 12,000 and 20,000 pounds for international students. Public universities have essentially been "marketized", obliged to sell themselves to student customers in a globally competitive market and invest in their image and branding. The higher fees paid by international students subsidize research as well as teaching. This explains why, whilst Brazil persisted with online-only teaching, British universities brought students back to campus for a promised mix of face-to-face and online teaching in September 2020, despite an emerging "second wave" of Covid-19 infections in Europe and scientists' warnings about the effects already observed after US campuses reopened. The University of Manchester even organized charter flights to bring in highpaying students from China, who make up one in eight of its student population. The epidemiological consequences of the reopening of campuses were predictably disastrous, for the host communities as well as the students themselves. Covid infection rates soared and tighter restrictions were imposed on local businesses. An unsatisfying "student experience" in terms of "value for money" and mishandled lockdowns in university accommodation produced student protests that management prioritized money over their safety and demands for fee and rent rebates. Protesting students received support from some staff, but many members of the public commenting on newspaper reports did not sympathize, grumbling about illegal student parties and privileged young people doing "useless" degrees in subjects such as literature. The contradictions of the "marketized" public university are but one of many revealed by a pandemic whose differential health impacts are clearly related to socio-economic and ethno-racial inequalities. The Johnson government may try to impose a return to "vocational" training related to the demands of the labour market for disadvantaged students for whom "widening access" policies opened doors to the kind of liberal university education previously restricted to middle- and upper-class students. Another warning for Brazil?

I will conclude this discussion by focusing on research assessment, an area in which much that was pioneered in Britain 
has been exported, even if it was often "lost in translation". In 1986, the Thatcher government instituted a periodic national evaluation of the quality of the research carried out in British universities that assigned a grade to each "unit of assessment", principally discipline-based departments in the initial iterations of the exercise. The grade received determined the size of the block grants institutions received from government to support research infrastructure and the salaries of permanent research staff, the baseline of a "dual support system" in which the remainder of funding for research projects comes from competitive grants awarded by the national research councils.

In the original "Research Assessment Exercise" (RAE), evaluation was based on peer review by specialist subject committees. The basic principle that emerged was that quality was more important than quantity: up to four publications by individual academics in each unit of assessment would be read and rated. Allowance was made for circumstances that might reduce individual "productivity" during a review period (such as childbirth). Yet problems arose from allowing units of assessment to exclude staff deemed not to be "research active" from their submission altogether, beyond the obvious one of equating the overall score of units with partial and complete submissions of staff. Managers might threaten individuals with transfer to "teaching only" contracts. Individuals might be excluded because their publications were not expected to score well. The entire RAE process promoted "gaming" in which maximising RAE scores took precedence over other academic considerations and institutions tried to boost their scores by hiring in "stars" from their rivals in the manner of football clubs. The RAE not only promoted competition between institutions, but damaged relations within institutions between colleagues when individuals were accused of "letting the team down" and harassed by line managers deficient in interpersonal skills despite the training they received in this area, often outsourced to private companies. It therefore laid the foundations for a regime of "competitive accountability" in academic life that has continued to tighten its hold (Watermeyer 2019).

Given the costs and administrative burdens of a peer review-based system, changes over time included grouping two or more units of assessment together as sub-panels of a main panel. This had some academic justification in terms of recognizing interdisciplinary research and obliging disciplines to think about standards in other fields, but in the next evaluation, 
to be concluded in March 2021, the number of sub-panels has been reduced to 34 and there are only 4 main panels, whereas in the 2008 RAE 67 sub-panels worked under the guidance of 15 main panels. Increasing emphasis on excellence at the international level led to the funding available being awarded in an increasingly selective way that favoured major research universities, weakening the dual support system's ability to give all academics some opportunity to do research and help smaller centres of excellence develop in less prestigious institutions.

After the 2008 RAE, the organization representing university institutions, Universities UK, pressed for expert peer review of publications to be replaced by a less costly and administratively burdensome evaluation on the basis of bibliometric data. But it was decided that expert peer review should remain the primary method of evaluation for the renamed 2014 Research Assessment Framework (REF), although judgements might also be "informed" by metrics in subject areas for which this was appropriate. This decision was reached after extensive consultation, publication of reports by bodies such as the British Academy, and the commissioning of pilot studies. The argument that bibliometric analysis worked better for natural sciences and mathematics than for social sciences and humanities was already well established. Scholars who mostly published books and book chapters were disadvantaged relative to those who published principally in journals in terms of the calculation of citation scores and "impact factors". Yet so were those who mostly disseminated their research through conference papers, such as computer scientists. That there were problems in basing evaluation on bibliometric measures even within the sciences was one of the issues reviewed in an international conference of metrics experts in Leiden in 2014, whose conclusions were published as the Leiden Manifesto in the journal Nature (Hicks, Wouters, et al. 2015).

Noting that some universities, from Scandinavia to China, were now allocating research funding or paying bonuses on the basis of individual impact scores or publication in "high impact journals", a criterion also increasingly used in recruitment and promotion cases, the Leiden Manifesto accepts that metrics can be useful for reducing bias in peer review, but provides a list of reasons why decision-making should not "be ceded to the numbers", even if it is clear what they mean, which is far from being the case given differences in citation practices between subfields (even in the natural and applied sciences) and 
the serious biases inherent in the construction of metric data. The first major citation database, which become the Web of Science, owned by Thompson Reuters, was very selective, often on less than transparent grounds, in which journals it chose to index, even within the English-speaking world. Its Elsevierowned rival Scopus presented similar problems. Citation rates and impact factors for journals differ widely between fields. Differences in citation practices affect the h-index scores of individual scholars working in different fields, but so do differences in the way the different databases are constructed: there can be big differences in the scores received by individuals in, for example, Web of Science and the somewhat more inclusive Google Scholar. Thompson-Reuters attempted to answer criticism from Latin America that the region's scholarly production was excluded from its index through partnership with SciELO, but even that meant that only a fraction of the region's research would obtain an impact factor. There were high hopes that "altmetrics", article level metrics captured from sources such as blogs, social media and Wikipedia, might provide a more globally democratic solution. Yet there are still problems in knowing what the measures mean (which means knowing more about the different kinds of "publics" actually reading the articles), as well as North Atlantic biases in ownership and use of altmetric sources (Alperin 2014). As the Leiden group observed, bias towards English-language publication in "high impact" Northern journals as a criterion for evaluating scholars everywhere in the world ignores the way that a good deal of research in the South is focused on specific kinds of regional and national problems and informing local policy, especially in the social sciences. Not only should excellence be protected in "locally relevant" research, but performance needs to be measured against the specific research missions of researchers and institutions, since advancing the frontiers of academic knowledge is not the same as delivering solutions to social problems (Hicks, Wouters, et al. 2015: 430).

Brazil, like many other countries and the European Union, has its own system of journal rankings, but the perverse consequences beyond North Atlantic bias that can arise from these systems are considerable, and can occur even in systems based on peer review panels, since reviewers' judgements may still be influenced by their ideas about "leading" journals and publishers in their field. One notorious case in the UK is Economics. Panel criteria led to the effective extinction of 
"heterodox economics" under the RAE, reinforcing the dominance of a select group of departments promoting neoclassical orthodoxy (Lee, Pham \& Gu 2013). Manchester students made national headlines by demanding teaching in heterodox approaches but remained unsatisfied by the response. As the economic consequences of the pandemic threaten to deepen pre-existing problems of inequality in capitalist societies, a more strategic vision would suggest that we now need all the heterodox thinking we can get in this field.

International benchmarking exercises might encourage a more strategic and deliberative approach to assessment. In 2005, I chaired the Steering Committee for the ESRC's first experiment in international benchmarking. Although the ESRC's head at the time, Ian Diamond, was a distinguished social statistician, he was as insistent as I was that the assessment should be qualitative. The work of the international panel commissioned to carry it out was informed by statistical data on the particularities of UK anthropology and the employment of its graduates compiled by David Mills, building on work the ASA had already done, but the main methodology was based on visits to a diverse group of anthropology departments. This allowed the team to talk at length to staff and students and apply their ethnographic skills, assuring colleagues that this was not a competitive exercise like the RAE. Visits were followed up by deliberative sessions discussing the results. Since the international panel chair, Don Brenneis, has published an account of this experience embedded in a broader comparative discussion of assessment of anthropology (Brenneis 2009), I will restrict myself to one conclusion in the final report (ESRC 2006). British anthropology was not only judged world-leading in a number of academic areas, but "extraordinary" in the interfaces that it had built between the academic world and areas where anthropological skills and sensibilities could be applied to, demonstrably, reshape policy, in particular, international development. The mainstream academic publication emphasis of the RAE made it difficult for the anthropology $\mathrm{PhDs}$ who went to work in development agencies to move back into academy, but academics who worked with development agencies did not lose their capacity for constructively critical analysis of the way that those organizations worked. Sadly, the Johnson government has merged the Department for International Development into the Foreign Office, and impending cuts to the aid budget are 
likely to include the international research collaboration schemes financed from it, of which Brazil has been a major beneficiary.

The major innovation in the 2014 REF was in fact the introduction of non-academic "impact" as a measure, contributing twenty-five percent to the final grade awarded to each unit of assessment, although this kind of "impact" was not demanded for all research done in the unit. The case for impact was made through a narrative. Watermeyer (2019) argues that what counted in impact assessment was the elegance and plausibility of the narratives offered, since the absence of clear criteria discouraged attempts to make a rigorous evaluation of the claims made in them. Stein (2018) argues that the problem with validation of impact was that it had to take the form of written recognition from an institution, governmental or nongovernmental, a procedure unsuitable for many forms of anthropological engagement with the people that they study. He also observes that emphasis on research projects sidelines the non-academic impacts of training students who will pursue careers outside anthropology and academia. Mitchell (2014) points out that there were implicit assumptions in this audit process about what constituted "good" impact in terms of "effect, change and benefit to society or the economy". He asked whether the powers directing the system of evaluation would consider the radical anti-capitalist activism of the late David Graeber as "good impact", but also pointed to the undiscussed problem of possible "bad" impacts, beginning with Napoleon Chagnon's relationship with the Yanomami. What might be considered "good" or "bad" impact clearly depends on a context of prevailing ideas. Both Mitchell and Stein show how and why assessment of non-academic "impact" remains troubling to a critical anthropological consciousness, even if many of us want to achieve it.

To conclude. The way universities are "governed" is a more serious problem than metrics per se. Numbers are essential in some types of anthropological research, especially if we want to make a contribution to public policy debate in the "post-truth" world of an Internet that offers all manner of pernicious alternatives to grounded knowledge. Yet by dividing and fragmenting us through "competitive accountability" audit culture limits our capacity to function as public intellectuals and denies the value to society of what Tim Ingold defines as scholarship, that which unites professors and students in an 
academic community dedicated to asking new questions and, collectively, looking for new answers.

\section{References}

ALPERIN, Juan Pedro. 2014. "Altmetrics Could Enable Scholarship from Developing Countries to Receive Due Recognition." LSE Blogs, March 10, 2014, https://blogs.lse.ac.uk/impactofsocialsciences/2014/03/1 0/altmetrics-for-developing-regions/.

BRENNEIS, Don. 2009. "Anthropology in and of the Academy: Assessment, and Our Field's Future". Social Anthropology 17(3):261-75.

ESRC. 2006. International Benchmarking Review of UK Social Anthropology. https://esrc.ukri.org/files/research/researchand-impact-evaluation/international-benchmarkingreview-of-uk-social-anthropology/.

HICKS, Diana; WOUTERS, Paul; WALTMAN, Ludo; RIJCKE, Sarah de; RAFOLS, Ismael. 2015. "Bibliometrics: The Leiden Manifesto for Research Metrics". Nature 520:429-31.

LEE, Frederic S; PHAM, Xuan; GU, Gyun. 2013. "The UK Research Assessment Exercise and the Narrowing of UK Economics". Cambridge Fournal of Economics 37(4):693-717.

LEMKE, Thomas. 2001. "The Birth of Bio-Politics: Michel Foucault's Lecture at the Collège de France on Neo-Liberal Governmentality". Economy and Society 30(2):190-207.

MITGHELL, Jon P. 2014. "Anthropologists Behaving Badly? Impact and the Politics of Evaluation in an Era of Accountability". Etnográfica 18(2):275-97.

ROSE, Nikolas. 1999. Powers of Freedom: Reframing Political Thought. Cambridge: Cambridge University Press.

SIVERTSEN, Gunnar. 2017. "Unique, but Still Best Practice? The Research Excellence Framework (REF) from an International Perspective". Palgrave Communications 3(1):1-6.

SHORE, Cris; WRIGHT, Susan. 1999. "Audit Culture and Anthropology: Neo-Liberalism in British Higher Education". The Fournal of the Royal Anthropological Institute 5(4):557-575. 
SHORE, Cris; WRIGHT, Susan. 2015. "Audit Culture Revisited: Rankings, Ratings, and the Reassembling of Society". Current Anthropology 56(3):421-44.

STEIN, Felix. 2018. "Anthropology's 'Impact': A Comment on Audit and the Unmeasurable Nature of Critique". Fournal of the Royal Anthropological Institute 24(1):10-29.

STRATHERN, Marilyn. 1996. "From Improvement to Enhancement: An Anthropological Comment on the Audit Culture". The Cambridge Fournal of Anthropology 19(7):1-21.

STRATHERN, Marilyn (ed.). 2000. Audit Cultures: Anthropological Studies in Accountability, Ethics and the Academy. London and New York: Routledge.

WATERMEYER, Richard. 2019. Competitive Accountability in Academic Life: The Struggle for Social Impact and Public Legitimacy. Cheltenham: Edward Elgar Publishing.

Submitted: 24 November 2020 Accepted: 1 December 2020 